\title{
Interferon alpha regulates MAPK and STAT1 pathways in human hepatoma cells
}

\author{
Lan-Juan Zhao ${ }^{\dagger}$, Xian Hua ${ }^{\dagger}$, Sheng-Fei He, Hao Ren and Zhong-Tian Qi ${ }^{*}$
}

\begin{abstract}
Background: Signaling events triggered by interferon (IFN) account for the molecular mechanisms of antiviral effect. JAK-STAT pathway plays a critical role in IFN signaling, and other pathways are also implicated in IFNmediated antiviral effect. Changes in mitogen-activated protein kinase (MAPK) and STAT1 pathways were evaluated in human hepatoma cells Huh7 and HepG2 upon IFN alpha treatment.

Results: Phosphorylation of ERK was significantly and specifically up-regulated, whereas enhanced phosphorylation of upstream kinase MEK was unobservable upon IFN alpha treatment. A mild increase in p38 MAPK, SAPK/JNK and downstream target ATF-2 phosphorylation was detectable after exposure to IFN alpha, indicating differential upregulation of the MAPK signaling cascades. Moreover, STAT1 phosphorylation was strongly enhanced by IFN alpha.
\end{abstract}

Conclusion: IFN alpha up-regulates MAPK and STAT1 pathways in human hepatoma cells, and may provide useful information for understanding the IFN signaling.

\section{Background}

Interferon (IFN), the first cytokine discovered in 1957 [1], has been studied extensively and advances have been made in biochemical and molecular mechanisms underlying production and action of IFN system. IFN family is classified as types I, II, and III, and plays a pivotal role in innate defense toward virus infection. Being the first line of defense, type I IFN including IFN alpha (IFN $\alpha$ ) and IFN beta, exert their potent antiviral activities immediately after virus infection by inhibiting viral replication and enhancing immune responses [2-4].

Signaling events triggered by IFN are involved in the molecular mechanisms of the antiviral effects. In particular, JAK-STAT pathway plays a critical role in the signaling events induced by IFN, and this pathway is initiated by IFN through interaction with cell surface specific receptors [5-7]. Upon IFN binding to its receptor, the receptor-associated tyrosine kinases JAK are phosphorylated and activated, the kinases subsequently activate transcription factors STAT, and the activated STAT translocate to nuclear followed by binding to IFN-stimulated response elements and modulating

\footnotetext{
* Correspondence: qizt@smmu.edu.cn

† Contributed equally

Department of Microbiology, Shanghai Key Laboratory of Medical Biodefense, Second Military Medical University, Shanghai, PR China
}

transcription of IFN-stimulated genes [8]. The products of IFN-stimulated genes are known to be responsible for the antiviral effects of IFN [9]. Apart from the JAKSTAT pathway, a number of pathways may also be important for the IFN-dependent biological responses. Mitogen-activated protein kinase (MAPK) signaling pathways are composed of three subfamilies including ERK, SAPK/JNK, and p38 MAPK, and activation of MAPK pathways contributes to some human diseases [10]. MAPK pathways are activated by a wide variety of extracellular signals such as stress, growth factors, and cytokines. The p38 MAPK or ERK is rapidly phosphorylated and activated in response to IFN $\alpha$ treatment $[11,12]$. However, involvement of MAPK pathways in the IFN signaling needs to be fully elucidated.

Hepatitis $\mathrm{C}$ virus (HCV) infection is the major cause of human liver diseases. IFN $\alpha$ is the current approved treatment for HCV infection [13]. We reported that the MAPK signaling pathways triggered by HCV envelope protein E2 were involved in the viral pathogenesis [14-16]. Since certain signaling events triggered by IFN $\alpha$ account for its antiviral effect, we wondered whether the MAPK pathways were also affected and an association between MAPK and STAT1 pathways under IFN $\alpha$ treatment. Difference in cellular response was evaluated after exposure to IFN $\alpha$. Human hepatoma cells are 
usually used as models for evaluation of the IFN signaling. Thus, the aim of this study is to reveal regulation of MAPK and STAT1 signaling pathways by IFN $\alpha$ in human hepatoma cells Huh7 and HepG2.

\section{Results}

\section{Influence of IFN $\alpha$ on MEK}

Activation of mitogen-activated protein kinases occurs through phosphorylation of threonine and tyrosine. Phosphorylation levels of kinases are usually evaluated to estimate MAPK pathways in response to stimuli [17-19]. To examine whether MEK-ERK pathway would be affected under IFN treatment, changes in MEK phosphorylation were initially analyzed by Western blotting. Huh7 and HepG2 cells were treated with the increasing concentrations of IFN $\alpha(0,100,200,400,800 \mathrm{U} / \mathrm{ml})$ for the indicated time course $(15,30,60 \mathrm{~min})$ and MEK phosphorylation was analyzed before and after the treatment. Figure 1A showed that level of MEK phosphorylation after the IFN $\alpha$ treatment was similar to that before

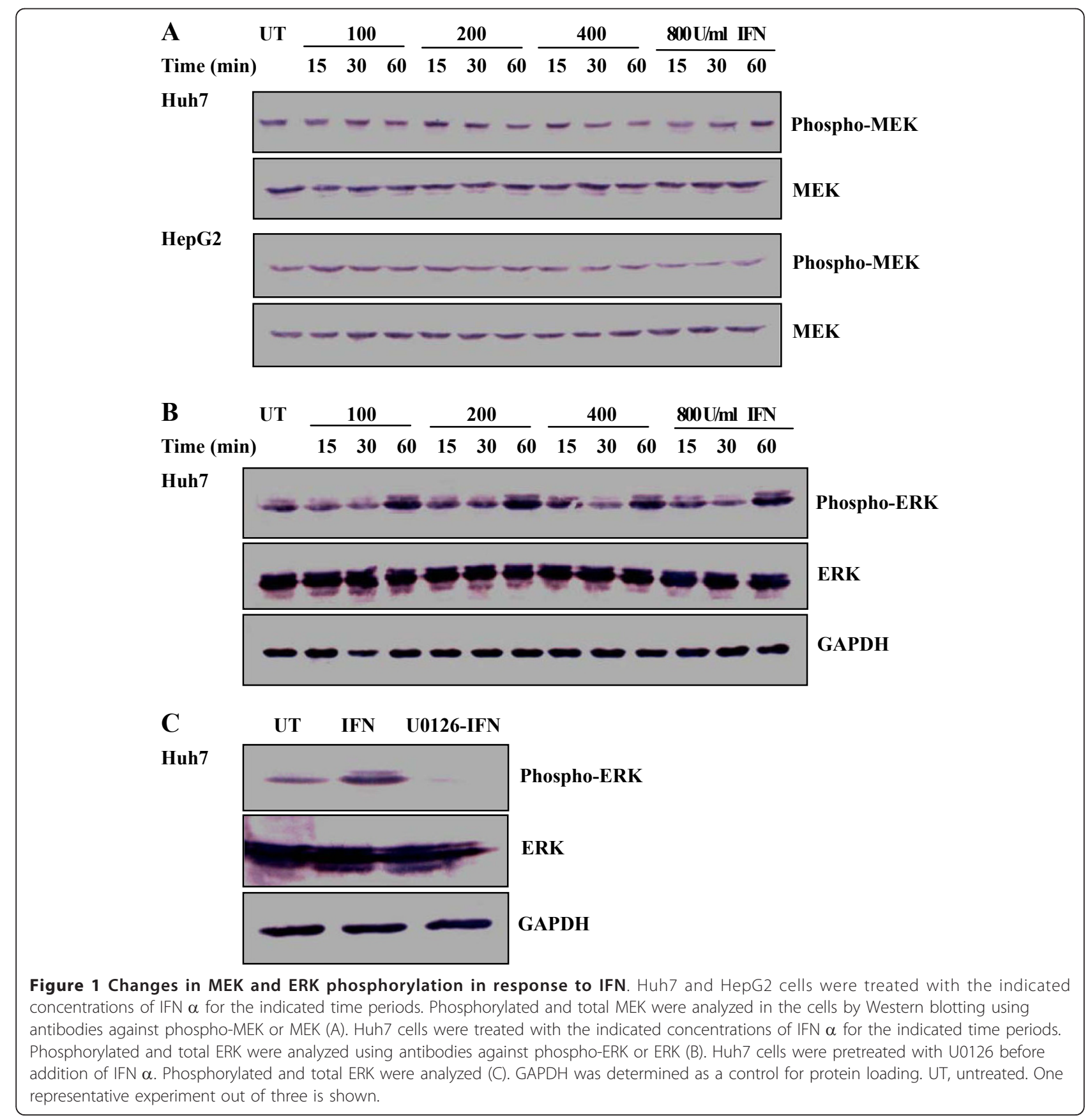


such treatment in Huh7 and HepG2 cells. For long time treatment of IFN, Huh7 cells were cultured in the medium containing the $800 \mathrm{U} / \mathrm{ml}$ IFN $\alpha$ for $12,24,48$, or 72 hrs. Compared with basal level of MEK phosphorylation without the IFN treatment, there was no increase in MEK phosphorylation with the IFN treatment for 12 or $24 \mathrm{hrs}$ and the kinase phosphorylation was reduced following the treatment for 48 or 72 hrs (Figure 4). Amount of total MEK, independent of phosphorylation, was monitored as a control for protein loading. IFN $\alpha$ seems to be no enhanced effect on MEK phosphorylation.

\section{Prevention of IFN $\alpha$-induced ERK activation by U0126}

Next, changes in downstream kinase ERK phosphorylation were estimated in Huh7 cells treated with the IFN $\alpha$. As shown in Figure 1B, phosphorylation of ERK was increased after exposure to the IFN. Upon the treatment with IFN $\alpha$ at concentrations ranging from 100 to $800 \mathrm{U} / \mathrm{ml}$, level of ERK phosphorylation was high after 15 min treatment compared to the treatment for $30 \mathrm{~min}$, and a significant increase in ERK phosphorylation was observed at $60 \mathrm{~min}$. In addition, MEK inhibitor U0126 was applied to estimate specific regulation of the kinase cascade by the IFN $\alpha$. Huh7 was pretreated with
$10 \mu \mathrm{M}$ U0126 prior to the addition of $100 \mathrm{U} / \mathrm{ml}$ IFN $\alpha$. Figure $1 \mathrm{C}$ showed that level of ERK phosphorylation was markedly decreased in the cells pretreated with the U0126, indicating that pretreatment with U0126 prevents the IFN $\alpha$-induced ERK phosphorylation. Constant level of total ERK was also determined. GAPDH was determined as a control for protein loading. Thus, IFN $\alpha$ significantly and specifically up-regulates ERK phosphorylation.

\section{Regulation of p38 MAPK, SAPK/JNK, and ATF-2 by IFN $\alpha$}

To evaluate effects of IFN on p38 MAPK and SAPK/ JNK, cell lysates from Huh7 and HepG2 treated with the different concentrations of IFN $\alpha$ at the indicated time points were examined by Western blot analysis. In comparison with phosphorylation of p38 MAPK without the IFN $\alpha$ treatment, level of p38 MAPK phosphorylation was slightly increased following the IFN $\alpha$ treatment (Figure 2). As for SAPK/JNK, differential profiles were observable in response to the IFN $\alpha$ treatment between HepG2 and Huh7. In HepG 2 cells, the IFN $\alpha$ had no obvious effect on SAPK/JNK phosphorylation. Whereas SAPK/JNK phosphorylation was enhanced by

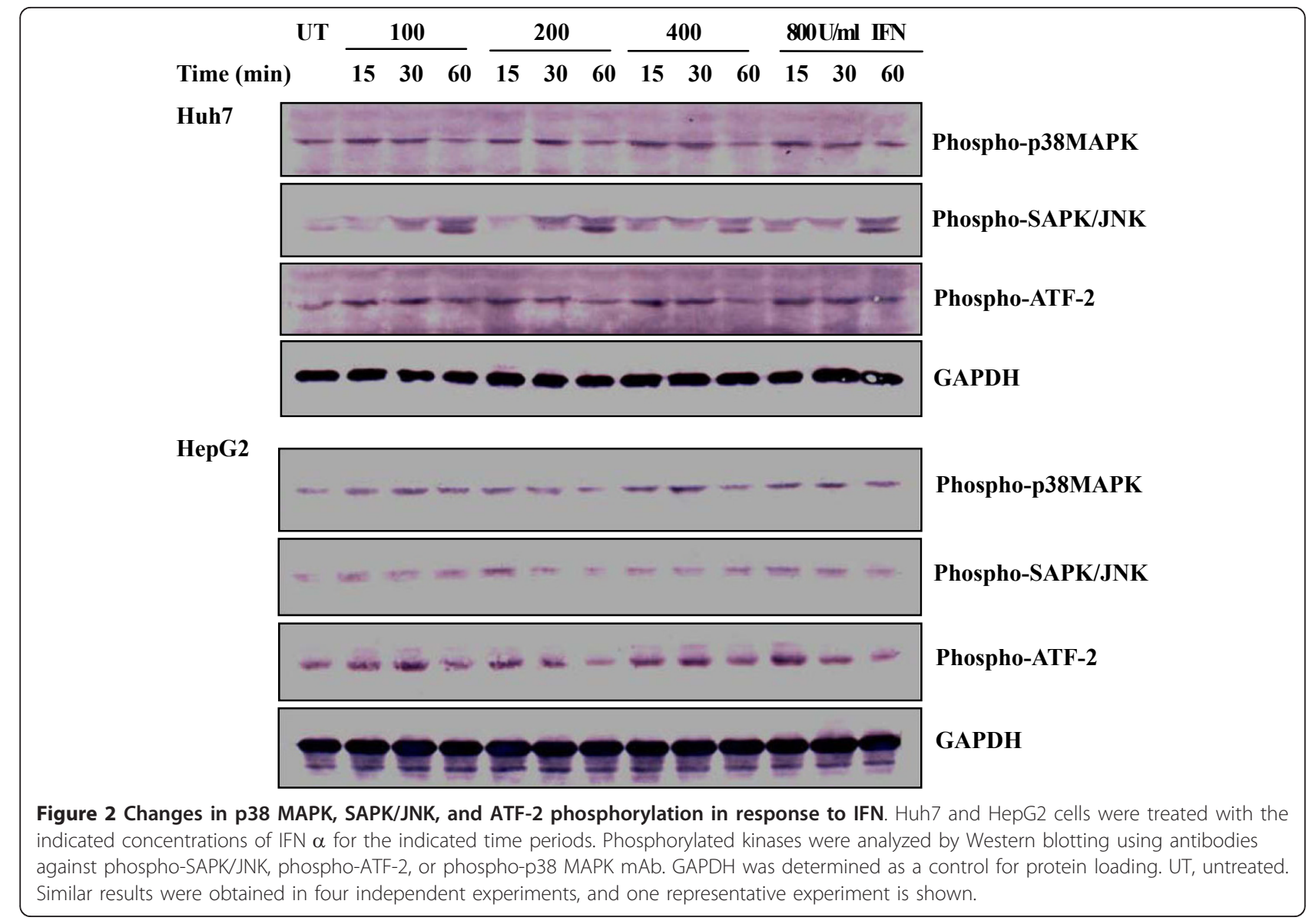


the IFN $\alpha$ in a time dependent-manner in Huh7 cells, and the IFN $\alpha$ treatment for $60 \mathrm{~min}$ led to a significant increase in SAPK/JNK phosphorylation. GAPDH was determined as a control for protein loading.

Transcription factor ATF-2 is a downstream target of p38 MAPK and SAPK/JNK pathways. SAPK/JNK and p38 MAPK are known to phosphorylate and activate ATF-2. Since the upstream kinases $\mathrm{p} 38$ MAPK and SAPK/JNK were activated by the IFN $\alpha$, changes in ATF-2 phosphorylation were thereby assessed. Figure 2 showed that the IFN $\alpha$ treatment caused a slight increase in ATF-2 phosphorylation. Interestingly, treatment of Huh7 with the IFN for 15 min seemed to be suitable for ATF-2 phosphorylation, which was consistent with the p38 MAPK phosphorylation. Thus, p38 MAPK, SAPK/JNK, and ATF-2 are differentially activated by IFN $\alpha$.

\section{Regulation of STAT1 by IFN $\alpha$}

Activation of STAT1 is involved in the classical IFN signaling pathways. Huh7 and HepG2 cells were treated with the increasing concentrations of IFN $\alpha$ for the indicated time course and phosphorylation of STAT1 was examined in the cells by Western blot analysis. Figure 3 showed that level of STAT1 phosphorylation was increased in response to the IFN $\alpha$ treatment, and such phosphorylation was enhanced by the IFN $\alpha$ in a concentration dependent-manner, as evidenced that $800 \mathrm{U} /$ $\mathrm{ml}$ IFN $\alpha$ treatment resulted in strong phosphorylation of STAT1 compared with the treatment of IFN $\alpha$ at the other concentrations. Moreover, phosphorylation of STAT1 was also increased upon the IFN $\alpha$ treatment for a long time period. In Huh7 cells, level of STAT1 phosphorylation was high following the $800 \mathrm{U} / \mathrm{ml}$ IFN $\alpha$ treatment for 12 or $24 \mathrm{hrs}$ compared to the treatment for 48 or $72 \mathrm{hrs}$ (Figure 4). As a control for protein loading, blots were probed with antibodies against STAT1. The data show that IFN $\alpha$ is responsible for the elevated STAT1 phosphorylation.

\section{Discussion}

Being the effective therapy for HCV infection, IFN $\alpha$ has been focused to reveal the molecular mechanisms underlying antiviral effect. Among the multiple mechanisms, modulation of the signaling events by IFN $\alpha$ is particularly important for the antiviral effect. In this report, we have investigated regulation of the MAPK and STAT1 signaling pathways by IFN $\alpha$ in human hepatoma cells. Our data show that the phosphorylation of ERK, p38 MAPK, SAPK/JNK, and ATF-2 is up-regulated by IFN $\alpha$, whereas IFN $\alpha$ seems to be no enhanced effect on the MEK phosphorylation. In response to IFN $\alpha$ treatment, the STAT1 phosphorylation is also enhanced. The profiles of kinetic kinase phosphorylation are shown.

IFN is believed to exert its antiviral effect predominantly through JAK-STAT signaling pathway. IFN sequentially phosphorylates and activates JAK kinases and STAT transcription factors to stimulate the transcription of IFN-stimulated genes. STAT family has seven known members, and STAT1 and STAT2 play central roles in induction of the IFN-dependent antiviral state [9]. Studies show that some viruses have evolved strategies to evade the host immune responses and set up successful infections by targeting STAT pathway. Ebola virus, rotavirus, Venezuelan equine encephalitis virus, Sindbis virus, and Marburg virus are shown to prevent the nuclear translocation and phosphorylation of STAT1, resulting in the impairment of the IFN $\alpha$-dependent

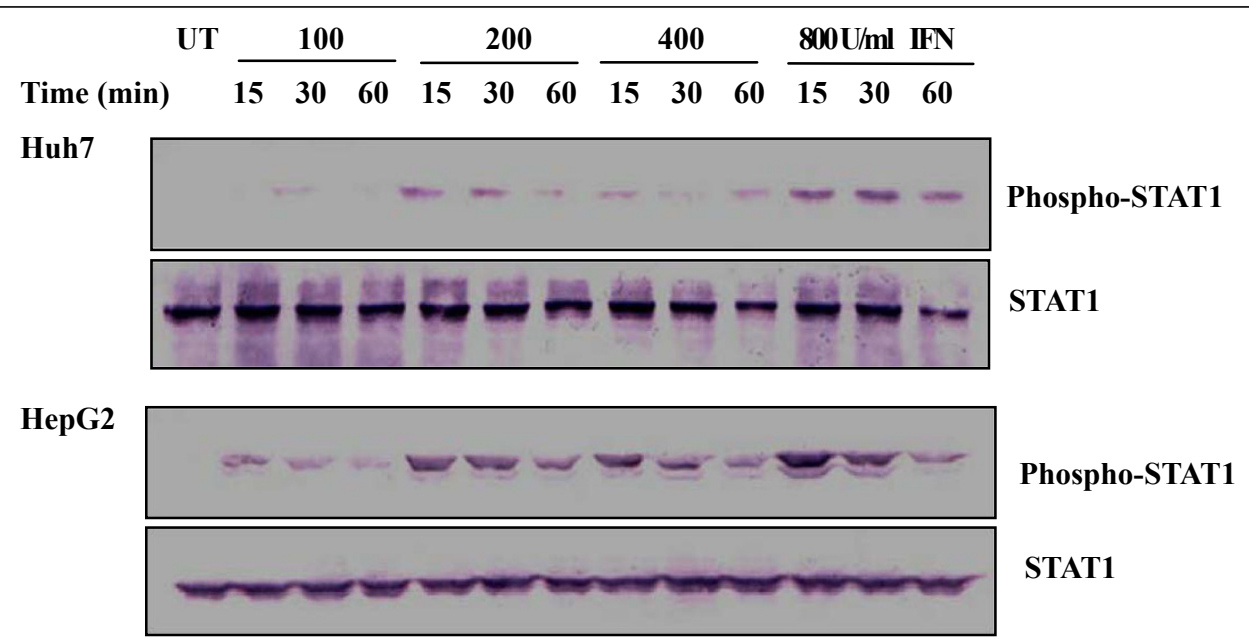

Figure 3 Changes in STAT1 phosphorylation in response to IFN. Huh7 and HepG2 cells were treated with the indicated concentrations of IFN $\alpha$ for the indicated time periods. Western blotting was performed to analyze phosphorylated and total STAT1 using antibody against phospho-STAT1 or STAT1. UT, untreated. Experiments were performed three times with similar results, and representative results are shown. 


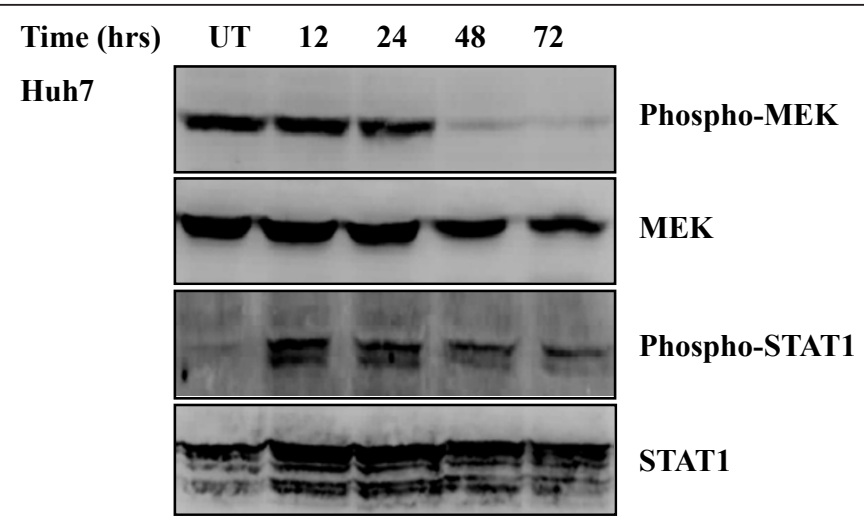

Figure 4 Kinetic changes in MEK and STAT1 phosphorylation after exposure to IFN. Huh7 cells were cultured in the DMEM containing the IFN $\alpha$ for $12,24,48$, and 72 hrs, respectively. Western blotting was performed to analyze phosphorylated and total MEK and STAT1. UT, untreated. One representative experiment out of five is shown.

antiviral effect [20-23]. As for HCV, the interference of $\mathrm{HCV}$ proteins with IFN $\alpha$-induced JAK-STAT pathway has been proposed to be an escape strategy of HCV [24]. For instance, HCV core protein inhibits IFN $\alpha$-induced activation of STAT1 in hepatic cells [25]. IFN $\alpha$ mediated STAT activation is blocked in Huh7 cells containing the HCV genomic replicon [26]. HCV nonstructural protein $5 \mathrm{~A}$ inhibits IFN $\alpha$ signaling through suppression of STAT1 phosphorylation in hepatocytederived cells [27]. Consistent with these findings, here we document that the STAT1 phosphorylation is strongly enhanced by IFN $\alpha$ in human hepatoma cells. Our data show that the phosphorylation of STAT1 is enhanced upon the IFN $\alpha$ treatment not only for a short time period but also for a long time period. These results are confirmed by using the IFN $\alpha-2 a$ and $2 b$.

Changes in the MAPK signaling pathways induced by the $\mathrm{HCV}$ proteins contribute to $\mathrm{HCV}$ pathogenesis. In this regards, it is interesting to examine whether MAPK pathways are also interfered by IFN $\alpha$ and the association between MAPK pathways and JAK-STAT pathway triggered by IFN $\alpha$. In the present study, we addressed the regulation of MEK, ERK, p38 MAPK, SAPK/JNK, and ATF- 2 by the IFN $\alpha$. The cellular response was evaluated upon the different concentrations and time periods of the IFN $\alpha$ treatment. The ERK pathway is activated by growth factors, cytokines, and virus infection. Interestingly, we found that the phosphorylation of ERK was significantly and specifically up-regulated by the IFN $\alpha$, whereas enhanced phosphorylation of upstream kinase MEK was unobservable. The p38 MAPK and SAPK/JNK are the stress-related signal transduction pathways. The IFN $\alpha$ treatment led to the mild increase in p38 MAPK and SAPK/JNK phosphorylation, and also resulted in the enhancement of downstream target ATF-2 phosphorylation. Our data indicate that IFN $\alpha$ is capable of differentially up-regulating
MAPK pathways in human hepatoma cells. Under the same condition of IFN $\alpha$ treatment, Huh7 appears to be susceptible to the IFN $\alpha$ compared with HepG2, implying that the regulation of MAPK pathways by IFN $\alpha$ may depend on cell types. In support of our data, reports show that the p38 MAPK, JNK, and ERK are activated by IFN gamma or the type I IFN [28-30]. Thus, in addition to classical JAK-STAT pathway, MAPK pathways are also activated by IFN $\alpha$ and involved in the IFN signaling. Recent studies illustrate an important role for the IFN signaling pathways in triggering the host antiviral responses to $\mathrm{HCV}$ infection [31-34]. Our results suggest that the up-regulation of MAPK and STAT1 pathways by IFN $\alpha$ might be implicated in its antiviral effect, although we have not ruled out the possible involvement of other pathways in the signaling events induced by IFN $\alpha$. Further studies are still necessary to determine the downstream effects of these phosphorylation events, including the doublestranded RNA-activated protein kinase, 2'-5' oligoadenylate synthetase, and Mx.

In conclusion, our results demonstrate that IFN $\alpha$ upregulates MAPK and STAT1 signaling pathways in human hepatoma cells, and provide useful information for understanding the IFN signaling events.

\section{Methods}

\section{Materials}

Recombinant human IFN $\alpha-2 \mathrm{a}$ and $2 \mathrm{~b}$ were obtained from PBL Interferon Source (Piscataway, NJ) and Huaxin High Biotechnology (Shanghai, China), respectively. Alkaline phosphatase-conjugated goat anti-rabbit or anti-mouse IgG were purchased from Vector Lab (Burlingame, CA). Horseradish peroxidase-conjugated goat anti-rabbit IgG was from Invitrogen (Camarillo, CA). Chemiluminescent detection reagents were from Millipore (Billerica, MA). 5-bromo-4-chloro-3-indolyl 
phosphate and nitroblue tetrazolium were obtained from Sigma (St. Louis, MO). MEK inhibitor U0126 and antibodies specific for MEK, ERK, STAT1, phospho-MEK (Ser217/221), phospho-ERK (Thr202/Tyr204), phosphoSAPK/JNK (Thr183/Tyr185), phospho-p38 MAPK (Thr180/Tyr182), phospho-ATF-2 (Thr71), or phosphoSTAT1 (Tyr701) were purchased from Cell Signaling Technology (Beverly, MA). Dulbecco's modified Eagle's medium (DMEM) and fetal bovine serum were from HyClone.

\section{IFN treatment}

Human hepatoma cells Huh7 and HepG2 were grown in DMEM plus $10 \%$ fetal bovine serum, $2 \mathrm{mM} \mathrm{L}$-glutamine, $100 \mathrm{U} / \mathrm{ml}$ penicillin, and $100 \mu \mathrm{g} / \mathrm{ml}$ streptomycin at $37^{\circ} \mathrm{C}$ with $5 \% \mathrm{CO}_{2}$. Cells at $80 \%$ confluence were washed twice with phosphate-buffered saline and then maintained for 24 hrs in serum-free DMEM before treatment with IFN $\alpha-2 b$. For concentration- and time-dependent stimulation of IFN, cells serum-starved were treated with increasing concentrations of IFN $\alpha-2 b$ dissolved in $0.1 \%$ bovine serum albumin $(0,100,200,400,800 \mathrm{U} / \mathrm{ml})$ for 15, 30, or $60 \mathrm{~min}$. For long time treatment of IFN, Huh7 cells were serum starved for $12 \mathrm{hrs}$ and then cultured in serum-free DMEM containing $800 \mathrm{U} / \mathrm{ml}$ IFN $\alpha$-2a for 12 , 24,48 , and $72 \mathrm{hrs}$, respectively. Following the above treatments, cells were washed with phosphate-buffered saline, collected by centrifugation at 2,000 rpm for $5 \mathrm{~min}$, lysed in sodium dodecyl sulfate sample buffer on ice, and heated for $5 \mathrm{~min}$ at $100^{\circ} \mathrm{C}$. Cell lysates were centrifuged at $12,000 \mathrm{rpm}$ for $10 \mathrm{~min}$ to remove cellular debris, mixed with sample loading buffer, boiled, and that equal amounts of protein extracts were subjected to Western blot analysis.

\section{U0126 pretreatment}

Huh7 cells serum-starved were pretreated for $1 \mathrm{~h}$ with $10 \mu \mathrm{M}$ U0126 dissolved in dimethylsulfoxide prior to treatment with $100 \mathrm{U} / \mathrm{ml}$ IFN $\alpha-2 b$ for another $1 \mathrm{~h}$. Cells with or without the U0126 pretreatment were harvested and lysed for measurement of ERK by Western blotting.

\section{Western blotting}

Phosphorylated and total levels of signal molecules were assayed by Western blotting following the manufacturer's protocol with some modification. In brief, cell lysates were loaded onto $10 \%$ sodium dodecyl sulfatepolyacrylamide gel electrophoresis. Proteins were separated and transferred onto nitrocellulose membranes. After blocking in 5\% nonfat milk for $1 \mathrm{~h}$, membranes were incubated overnight at $4^{\circ} \mathrm{C}$ with antibodies against MEK, ERK, STAT1, phospho-MEK, phospho-ERK, phospho-SAPK/JNK, phospho-p38 MAPK, phospho-
ATF-2, or phospho-STAT1 at the recommended dilutions, followed by incubation with alkaline phosphatase or horseradish peroxidase-conjugated secondary antibodies. The blots were developed with 5-bromo-4-chloro3 -indolyl phosphate and nitroblue tetrazolium substrates or chemiluminescent detection reagents. Glyceraldehyde-3-phosphate dehydrogease (GAPDH) was determined as a control for protein loading.

\section{Acknowledgements}

This work was supported by the National Natural Science Foundation of China Grants (30771928, 30600529, 30921006), National Key Basic Research and Development (973) Program of China (2009CB522503), National S\&T Major Project for Infectious Diseases (2008ZX10002-13), and the Shanghai Leading Academic Discipline Project (B901).

\section{Authors' contributions}

LIZ designed and performed research, analyzed and interpreted data, and wrote the manuscript. XH, SFH, and HR performed research. ZTQ has given final approval for the version to be published. All authors read and approved the final manuscript.

\section{Competing interests}

The authors declare that they have no competing interests.

Received: 2 September 2010 Accepted: 6 April 2011

Published: 6 April 2011

\section{References}

1. Isaacs A, Lindenmann J: Virus interference. I. The interferon. Proc $R$ Soc Lond B Biol Sci 1957, 147:258-267.

2. Baron S, Dianzani F: The interferons: a biological system with therapeutic potential in viral infections. Antiviral Res 1994, 24:97-110.

3. Capobianchi MR, Abbate I, Cappiello G, Solmone M: HCV and interferon: viral strategies for evading innate defence mechanisms in the virus-host battle. Cell Death Differ 2003, 10(Suppl 1):S22-24.

4. Akira S, Uematsu S, Takeuchi O: Pathogen recognition and innate immunity. Cell 2006, 124:783-801.

5. Darnell JE Jr, Kerr IM, Stark GR: Jak-STAT pathways and transcriptional activation in response to IFNs and other extracellular signaling proteins. Science 1994, 264:1415-1421.

6. Stark GR, Kerr IM, Williams BR, Silverman RH, Schreiber RD: How cells respond to interferons. Annu Rev Biochem 1998, 67:227-264.

7. de Weerd NA, Samarajiwa SA, Hertzog PJ: Type I interferon receptors: biochemistry and biological functions. J Biol Chem 2007, 282:20053-20057.

8. Sarasin-Filipowicz M, Oakeley EJ, Duong FH, Christen V, Terracciano L, Filipowicz W, Heim MH: Interferon signaling and treatment outcome in chronic hepatitis C. Proc Natl Acad Sci USA 2008, 105:7034-7039.

9. Samuel CE: Antiviral actions of interferons. Clin Microbiol Rev 2001, 14:778-809.

10. Johnson GL, Lapadat R: Mitogen-activated protein kinase pathways mediated by ERK, JNK, and p38 protein kinases. Science 2002, 298:1911-1912

11. Uddin S, Majchrzak B, Woodson J, Arunkumar P, Alsayed Y, Pine R, Young PR, Fish EN, Platanias LC: Activation of the p38 mitogen-activated protein kinase by type I interferons. J Biol Chem 1999, 274:30127-30131.

12. Arora T, Floyd-Smith G, Espy MJ, Jelinek DF: Dissociation between IFNalpha-induced anti-viral and growth signaling pathways. J Immunol 1999, 162:3289-3297.

13. Hoofnagle $\mathrm{JH}$, di Bisceglie AM: The treatment of chronic viral hepatitis. $N$ Engl J Med 1997, 336:347-356.

14. Zhao LJ, Wang L, Ren H, Cao J, Li L, Ke JS, Qi ZT: Hepatitis C virus E2 protein promotes human hepatoma cell proliferation through the MAPK/ERK signaling pathway via cellular receptors. Exp Cell Res 2005, 305:23-32.

15. Zhao LJ, Zhang XL, Zhao P, Cao J, Cao MM, Zhu SY, Liu HQ, Qi ZT: Upregulation of ERK and p38 MAPK signaling pathways by hepatitis $C$ virus 
E2 envelope protein in human T lymphoma cell line. J Leukoc Biol 2006, 80:424-432.

16. Zhao LJ, Zhao P, Chen QL, Ren H, Pan W, Qi ZT: Mitogen-activated protein kinase signaling pathways triggered by the hepatitis $C$ virus envelope protein E2: implications for the prevention of infection. Cell Proliferat 2007, 40:508-521.

17. Rosa D, Saletti G, De Gregorio E, Zorat F, Comar C, D'Oro U, Nuti S, Houghton M, Barnaba V, Pozzato G, Abrignani S: Activation of naïve B lymphocytes via CD81, a pathogenetic mechanism for hepatitis $C$ virusassociated B lymphocyte disorders. Proc Natl Acad Sci USA 2005, 102:18544-18549.

18. Choi SH, Park KJ, Ahn BY, Jung G, Lai MM, Hwang SB: Hepatitis C virus nonstructural $5 B$ protein regulates tumor necrosis factor alpha signaling through effects on cellular IkappaB kinase. Mol Cell Biol 2006, 26:3048-3059

19. Huang Y, Chen XC, Konduri M, Fomina N, Lu J, Jin L, Kolykhalov A, Tan SL: Mechanistic link between the anti-HCV effect of interferon gamma and control of viral replication by a Ras-MAPK signaling cascade. Hepatology 2006, 43:81-90.

20. Basler CF, Amarasinghe GK: Evasion of interferon responses by Ebola and Marburg viruses. J Interferon Cytokine Res 2009, 29:511-520.

21. Sherry B: Rotavirus and reovirus modulation of the interferon response. $J$ Interferon Cytokine Res 2009, 29:559-567.

22. Simmons JD, White $L$, Morrison TE, Montgomery SA, Whitmore AC, Johnston RE, Heise MT: Venezuelan equine encephalitis virus disrupts STAT1 signaling by distinct mechanisms independent of host shutoff. J Virol 2009, 83:10571-10581.

23. Yin J, Gardner CL, Burke CW, Ryman KD, Klimstra WB: Similarities and differences in antagonism of neuron alpha/beta interferon responses by Venezuelan equine encephalitis and Sindbis alphaviruses. J Virol 2009, 83:10036-10047.

24. Heim MH, Moradpour D, Blum HE: Expression of hepatitis C virus proteins inhibits signal transduction through the Jak-STAT pathway. J Virol 1999, 73:8469-8475.

25. Bode JG, Ludwig S, Ehrhardt C, Albrecht U, Erhardt A, Schaper F, Heinrich PC, Häussinger D: IFN-alpha antagonistic activity of HCV core protein involves induction of suppressor of cytokine signaling-3. FASEB J 2003, 17:488-490.

26. Luquin E, Larrea E, Civeira MP, Prieto J, Aldabe R: HCV structural proteins interfere with interferon-alpha Jak/STAT signalling pathway. Antiviral Res 2007, 76:194-197.

27. Lan KH, Lan KL, Lee WP, Sheu ML, Chen MY, Lee YL, Yen SH, Chang FY, Lee SD: HCV NS5A inhibits interferon-alpha signaling through suppression of STAT1 phosphorylation in hepatocyte-derived cell lines. J Hepatol 2007, 46:759-767.

28. Valledor AF, Sánchez-Tilló E, Arpa L, Park JM, Caelles C, Lloberas J, Celada A: Selective roles of MAPKs during the macrophage response to IFNgamma. J Immunol 2008, 180:4523-4529.

29. Jeon YJ, Choi JS, Lee JY, Yu KR, Kim SM, Ka SH, Oh KH, Kim KI, Zhang DE, Bang OS, Chung CH: ISG15 modification of filamin B negatively regulates the type I interferon-induced JNK signalling pathway. EMBO Rep 2009, 10:374-380.

30. Zhou Z, Hamming OJ, Ank N, Paludan SR, Nielsen AL, Hartmann R: Type III interferon (IFN) induces a type I IFN-like response in a restricted subset of cells through signaling pathways involving both the Jak-STAT pathway and the mitogen-activated protein kinases. J Virol 2007, 81:7749-7758.

31. He $Y$, Katze MG: To interfere and to anti-interfere: the interplay between hepatitis C virus and interferon. Viral Immunol 2002, 15:95-119.

32. Ishida H, Ohkawa K, Hosui A, Hiramatsu N, Kanto T, Ueda K, Takehara T, Hayashi N: Involvement of p38 signaling pathway in interferon-alphamediated antiviral activity toward hepatitis C virus. Biochem Biophys Res Commun 2004, 321:722-727.

33. Helbig KJ, Yip E, McCartney EM, Eyre NS, Beard MR: A screening method for identifying disruptions in interferon signaling reveals HCV NS3/4a disrupts Stat-1 phosphorylation. Antiviral Res 2008, 77:169-176.

34. Murao K, Imachi H, Yu X, Cao WM, Nishiuchi T, Chen K, Li J, Ahmed RA Wong NC, Ishida T: Interferon alpha decreases expression of human scavenger receptor class $\mathrm{Bl}$, a possible $\mathrm{HCV}$ receptor in hepatocytes. Gut 2008, 57:664-671.
doi:10.1186/1743-422X-8-157

Cite this article as: Zhao et al.: Interferon alpha regulates MAPK and STAT1 pathways in human hepatoma cells. Virology Journal 2011 8:157.

\section{Submit your next manuscript to BioMed Central and take full advantage of:}

- Convenient online submission

- Thorough peer review

- No space constraints or color figure charges

- Immediate publication on acceptance

- Inclusion in PubMed, CAS, Scopus and Google Scholar

- Research which is freely available for redistribution

Submit your manuscript at www.biomedcentral.com/submit
C Biomed Central 